\title{
Pi 1 Magnetic Pulsations Observed in Association with Low Latitude Aurora
}

\author{
Yoshihiro HIGUCHI \\ Department of Electronics and Information Engineering, Yamagata University, Yonezawa, Yamagata 992, Japan
}

(Received October 11, 1992; Revised May 17, 1993; Accepted July 5, 1993)

\begin{abstract}
Irregular magnetic pulsations and IPDP plasma wave events related to the low latitude aurora were observed at Yonezawa observatory on October 20 and 21, 1989. Three positive bays appeared in the magnetograms on October 20. Concurrently, IPDP, $\mathrm{Pi} 2, \mathrm{Pi} B$ and $\mathrm{Pi} C$ are registered during the respective positive bays. The power spectrum estimations of irregular magnetic pulsations are carried out by the maximum entropy method indicating that the spectral peaks are mainly distributed in the frequency band between $0.1 \mathrm{~Hz}$ and $0.2 \mathrm{~Hz}$. When the magnetopause is compressed by a sudden increase of the solar wind pressure inside the geosynchronous orbit, transient magnetic field oscillations are observed on the ground. Two distinct positive bays at the time of the minimum $H$ during the main phase of the geomagnetic storm occurred in the magnetograms on October 21 . The irregular magnetic pulsations accompanying the IPDP plasma wave events and the low latitude optical aurora were observed during each positive bays.
\end{abstract}

\section{Introduction}

Irregular magnetic pulsations have a close relationship with geomagnetic storms and substorms (see reviews by SAITO, 1969; GENDRIN, 1970; JACOBS, 1970; ROSTOKER, 1979; HEACOCK and HUNSUCKER, 1981; SAMSON, 1991). In particular, much attention has been paid to Pi 2 magnetic pulsations, since $\mathrm{Pi} 2$ magnetic pulsations occur at the onset of substorm's expansive phase. But, $\mathrm{Pi} 1$ magnetic pulsations also have a tendency to occur at the same time. The source mechanisms of $\mathrm{Pi} 1$ magnetic pulsations may be classified into three categories; (a) fluctuations in ionospheric currents and field-aligned currents occurring during substorms (CAMPBELL and MATSUSHITA, 1962; WILHELM et al., 1977; KANGAS et al., 1979; ENGEBRETSON et al., 1983), (b) cavity resonance model and field line resonance model (LYSAK, 1988; YUMOTO et al., 1989), (c) plasma microinstabilities at the inner edge of the plasma sheet (CORONITI and KENNEL, 1970; KAN and HEACOCK, 1976).

HEACOCK (1967) recognized that there exist two subtypes of Pi 1 magnetic pulsations; impulsive burstlike pulsations ( $\mathrm{Pi} \mathrm{B}$ ) occurring mainly in the midnight sector and more continuous pulsations (Pi C) occurring in the morning sector. A possible source of $\mathrm{Pi} \mathrm{B}$ is thought to be charged particle precipitations from the tail region of the magnetosphere, since $\mathrm{Pi} B$ is associated with impulsive cosmic noise absorption events. On the other hand, Pi C may be generated by the ionospheric currents associated with auroral electrojets.

At the present time, because of a rare occurrence of low latitude aurora, very little is known about observational and theoretical understanding of the properties of Pi 1 magnetic pulsations observed in association with the low latitude aurora. Therefore, a source of $\mathrm{Pi} 1$ magnetic pulsations related to the low latitude aurora is still one of unresolved problems. The purpose of this study is to report a preliminary analysis of irregular magnetic pulsations and IPDP plasma wave events observed in association with low latitude aurora on October 20 and 21, 1989.

Fortunately, there was an opportunity to observe a low latitude optical aurora in the northern area of Hokkaido island. A sudden commencement accompanying a great geomagnetic storm occurred at $09 \mathrm{~h} 17 \mathrm{~m}$ UT, on October 20,1989. During the main phase of the geomagnetic storm, bright red aurorae were observed twice in intervals of $11 \mathrm{~h} 10 \mathrm{~m}-12 \mathrm{~h} 30 \mathrm{~m} \mathrm{UT}$ and $14 \mathrm{~h} 10 \mathrm{~m}-14 \mathrm{~h} 25 \mathrm{~m}$ UT on October 21,1989 
(MIYAOKA et al., 1990). After a homogeneous dark red aurora appeared at $11 \mathrm{~h} 10 \mathrm{~m}$ UT, the sudden brightening occurred at $11 \mathrm{~h} 36 \mathrm{~m}$ UT. Several columns of ray structure with life time of a few 10 seconds were observed along the geomagnetic line of force during the active period. Concurrently, the $H$ component of magnetic field on the ground showed a northward excursion (positive bay). The Pi 1-2 magnetic pulsations and IPDP plasma wave events observed in association with the low latitude aurora, were registered at Yonezawa observatory.

Heretofore, a possible source of low latitude aurora has been believed to result from heat conduction of ring current particles which is different from polar aurora in the high latitudes. The reason is that the polar aurora in the high latitudes is mainly excited by a few Kev electrons, but the low latitude aurora is excited by large fluxes of low energy soft electrons with the energy of a few ev. The spectral characteristics of low latitude aurora is $6300 \AA$ line of Oxygen with the intensity of several kR and the enhancement of $5577 \AA$ emissions. But, the source of low energy soft electrons for low latitude aurora may be different from the source of electrons for stable auroral red (SAR) arcs (TINSLEY et al., 1986). The SAR arcs are generated at the plasmapause as a consequence of the turbulent dissipation of ring current energy (CORNWALl, 1970; CORNWALl et al., 1971). The SAR arcs are narrow in latitude and encircle the earth in longitude. The duration of SAR arcs is more than many hours (-day). Particularly, the SAR arcs have a tendency to occur during magnetically quiet conditions, i.e., during the recovery phase of geomagnetic storm. The low latitude aurora, by contrast, is when the duration is relatively short (-hour), and the low latitude aurora occurs in active magnetic conditions, during the main phase of a great geomagnetic storm. The low latitude aurora seems to be related to a particular magnetic perturbation and irregular magnetic pulsation accompanying the IPDP plasma wave event.

\section{Ground Observations and Power Spectrum Estimation}

Table 1 gives a list of the observatories used in this study along with their code names and geomagnetic coordinates. The $H$-component magnetic perturbations in the magnetograms on October 20 , 1989, from the north to the south observatories are shown in Fig. 1. It is clearly seen that three times of rapid northward excursions (positive bays) which indicate the occurrences of negative bays at high latitude in the time intervals of $13 \mathrm{~h} 36 \mathrm{~m}-15 \mathrm{~h} 00 \mathrm{~m}, 16 \mathrm{~h} 10 \mathrm{~m}-18 \mathrm{~h} 00 \mathrm{~m}$, and $18 \mathrm{~h} 35 \mathrm{~m}-19 \mathrm{~h} 50 \mathrm{~m}$ UT. Figure 2 shows an example of irregular magnetic pulsations observed at four observatories (MMB, ONG, YNZ and $\mathrm{KNY}$ ) which correspond to the second positive bay occurred at $16 \mathrm{~h} 10 \mathrm{~m}$ UT, October 20,1989 . Figure 3 shows filtered data observed at YNZ observatory. The data in the top panel are filtered in the frequency below $0.1 \mathrm{~Hz}$ to show Pi 2 magnetic pulsations. The data in the middle panel are filtered in the frequency band between $0.1 \mathrm{~Hz}$ and $0.2 \mathrm{~Hz}$ to highlight rapid fluctuations with the frequency of $0.15 \mathrm{~Hz}$. The data shown in the bottom panel are wave packets where the time scale is expanded in order to see how the amplitude of wave packets changes with time.

The power spectrum estimation for the irregular magnetic pulsations is carried out by the maximum

Table 1. Permanent or temporary stations from which data have been used in the present study.

\begin{tabular}{|c|c|c|c|c|c|}
\hline \multirow[t]{2}{*}{ Station } & \multirow[t]{2}{*}{ Symbol } & \multicolumn{2}{|c|}{ Geographic } & \multicolumn{2}{|c|}{ Geomagnetic } \\
\hline & & Latitude & Longitude & Latitude & Longitude \\
\hline Moshiri & MSR & $44.4^{\circ} \mathrm{N}$ & $142.3^{\circ} \mathrm{E}$ & $34.7^{\circ} \mathrm{N}$ & $208.3^{\circ} \mathrm{E}$ \\
\hline Memambetsu & MMB & $43.9^{\circ} \mathrm{N}$ & $144.2^{\circ} \mathrm{E}$ & $34.6^{\circ} \mathrm{N}$ & $210.2^{\circ} \mathrm{E}$ \\
\hline Onagawa & ONG & $38.4^{\circ} \mathrm{N}$ & $141.5^{\circ} \mathrm{E}$ & $28.8^{\circ} \mathrm{N}$ & $208.5^{\circ} \mathrm{E}$ \\
\hline Yonezawa & YNZ & $37.5^{\circ} \mathrm{N}$ & $140.1^{\circ} \mathrm{E}$ & $27.5^{\circ} \mathrm{N}$ & $205.6^{\circ} \mathrm{E}$ \\
\hline Kakioka & KAK & $36.2^{\circ} \mathrm{N}$ & $140.2^{\circ} \mathrm{E}$ & $26.6^{\circ} \mathrm{N}$ & $207.8^{\circ} \mathrm{E}$ \\
\hline Kanoya & $\mathrm{KNY}$ & $31.4^{\circ} \mathrm{N}$ & $130.9^{\circ} \mathrm{E}$ & $21.1^{\circ} \mathrm{N}$ & $199.8^{\circ} \mathrm{E}$ \\
\hline
\end{tabular}




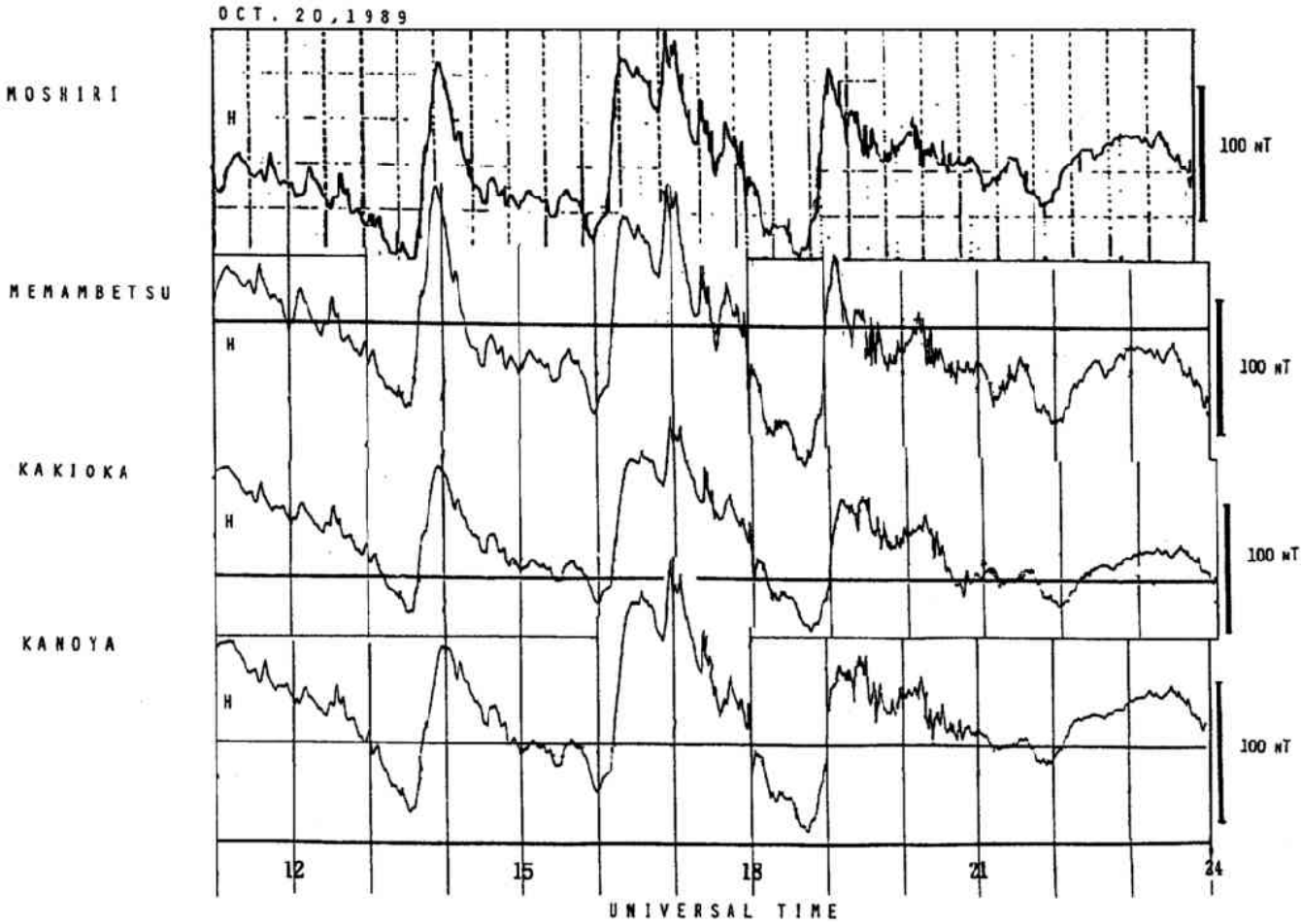

Fig. 1. The $H$-component magnetic perturbations in the magnetograms on October 20,1989 . Three positive bays with rapid intensifications are clearly seen in the time intervals of $13 \mathrm{~h} 36 \mathrm{~m}-15 \mathrm{~h} 00 \mathrm{~m}, 16 \mathrm{~h} 10 \mathrm{~m}-18 \mathrm{~h} 00 \mathrm{~m}$ and $18 \mathrm{~h} 35 \mathrm{~m}-20 \mathrm{~h} 00 \mathrm{~m}$ UT.
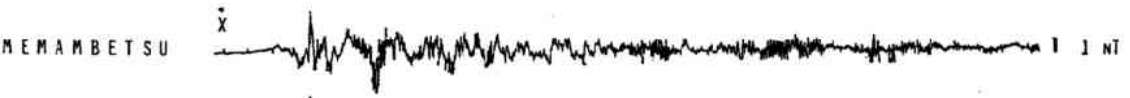

$O$ I A G A WA

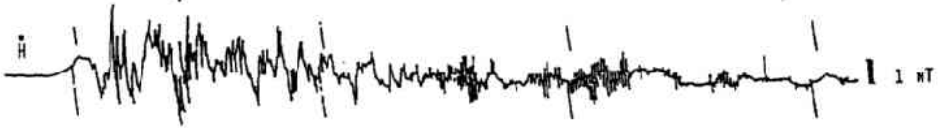

YONEZA WA

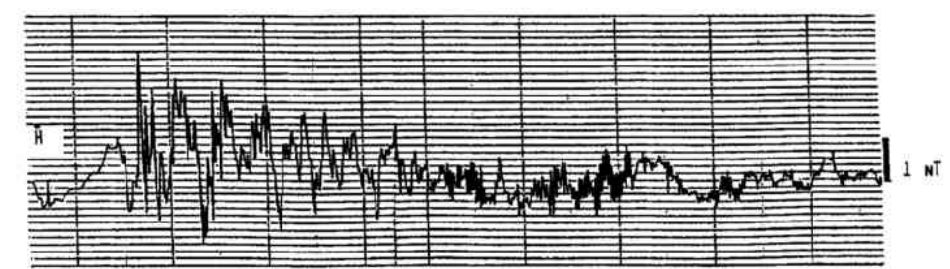

KANOYA

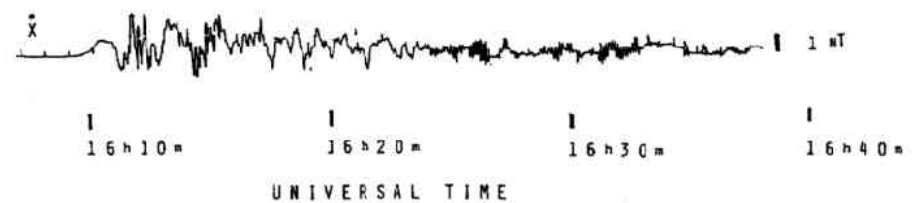

Fig. 2. An example of $\mathrm{Pi} 2$ magnetic pulsations accompanying the IPDP plasma wave event. Note that the high frequency wave packets appear after Pi 2 magnetic pulsations die out. 

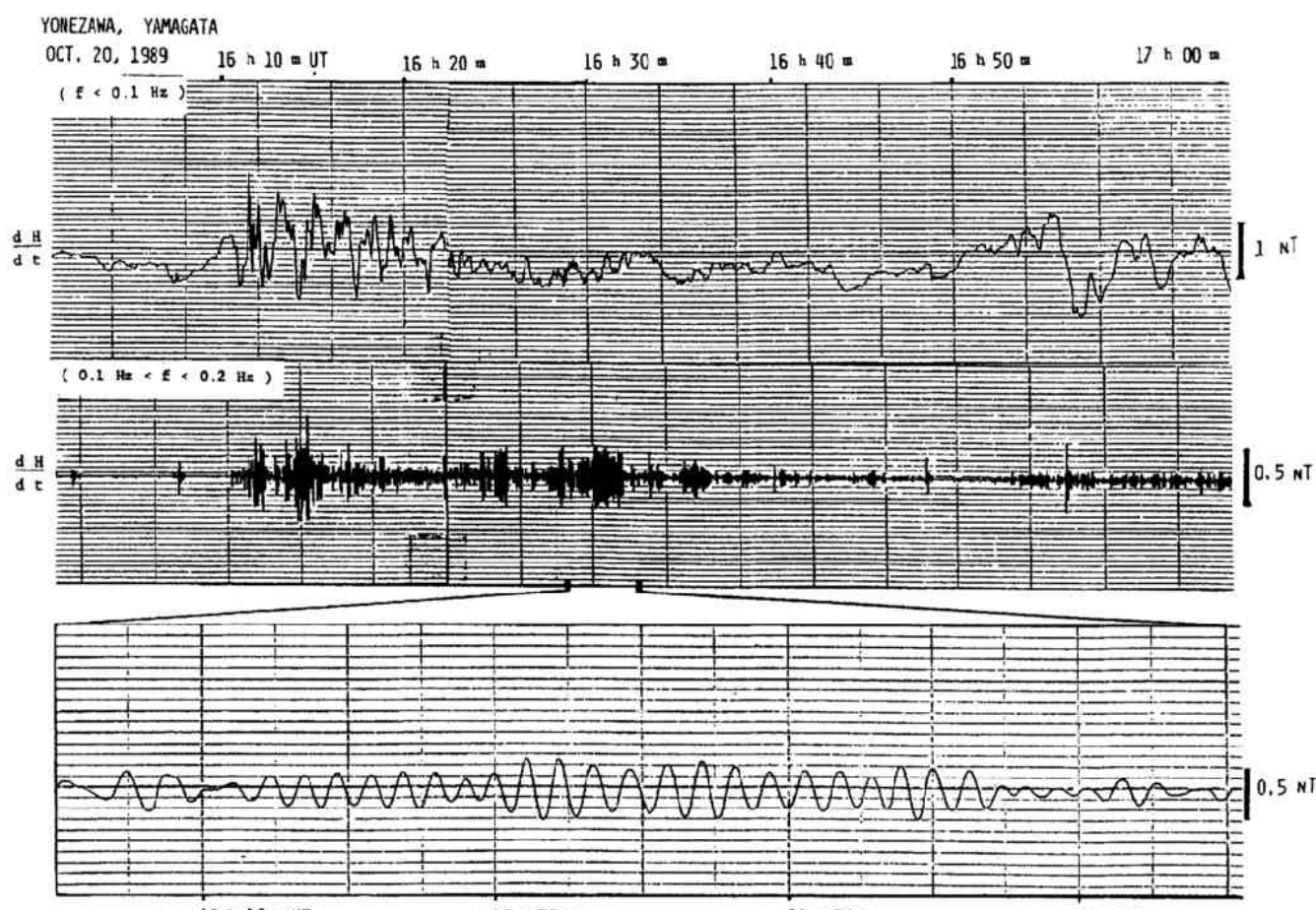

16 h 29 a UT

16 h $30 \mathrm{~m}$

16 h $31 \mathrm{~m}$

16 h 32 m

Fig. 3. Filtered data observed at YNZ observatory; The data in the top panel are filtered in the frequency below $0.1 \mathrm{~Hz}$, the data in the middle panel are filtered in the frequency band between $0.1 \mathrm{~Hz}$ and $0.2 \mathrm{~Hz}$ and the data in the bottom panel are the expansion of time scale for the high frequency wave packets.

entropy method. The analog outputs of induction magnetometer are sampled at 1 second intervals. Each spectrum is analyzed at every 15 minute interval and the separation between successive spectra is 0.2 minutes. The dynamic power spectrum estimation for wave packets in the time interval of $16 \mathrm{~h} 23 \mathrm{~m}-$ $16 \mathrm{~h} 38 \mathrm{~m}$ UT is shown in Fig. 4. The spectral peaks are coded according to a logarithmic gray scale with normalization of the maximum value. The result of power spectrum estimation indicates that the magnetic pulsations with the frequency of $0.15 \mathrm{~Hz}$ are clearly seen in the time interval around $16 \mathrm{~h} 30 \mathrm{~m}$ UT. One more interesting feature is that the magnetic pulsations with frequency of $0.15 \mathrm{~Hz}$ is superposed on the low frequency fluctuations with a frequency of $0.025 \mathrm{~Hz}$.

Another example of irregular magnetic pulsations observed at YNZ observatory during the third positive bay is shown in Fig. 5. Similarly, the data in the top panel are filtered in the frequency below 0.1 $\mathrm{Hz}$ to show the low frequency magnetic pulsations. The format of presentation in the middle and bottom panels is the same as in Fig. 3. The power spectrum estimation for the irregular magnetic pulsations $(\mathrm{PiC})$ is also carried out by the maximum entropy method. Each spectrum is analyzed at every 5 minute interval and the separation of successive spectra is 0.5 minutes in this case. The dynamic power spectrum in the time interval of $18 \mathrm{~h} 46 \mathrm{~m}-19 \mathrm{~h} 26 \mathrm{~m}$ UT is shown in Fig. 6 . The result of power spectrum estimation shows that the spectral peaks around $19 \mathrm{~h} 00 \mathrm{~m}$ UT are mainly distributed from the frequency of $0.1 \mathrm{~Hz}$ to $0.3 \mathrm{~Hz}$.

Figure 7 shows the $H$-component of magnetograms from four observatories (MSR, MMB, KAK and KNY) on October 21,1989 . The geomagnetic storm is developing with a rapid intensification and the amplitude of the minimum of $H$ reached to approximately $-320 \mathrm{nT}$ at $11 \mathrm{~h} 30 \mathrm{~m}$ UT. Two distinct positive bays with $H>150 \mathrm{nT}$ magnitude are observed at all four observatories which are shown in the shaded portions in the magnetograms. The maximum amplitude decreases upon decreasing the observational 


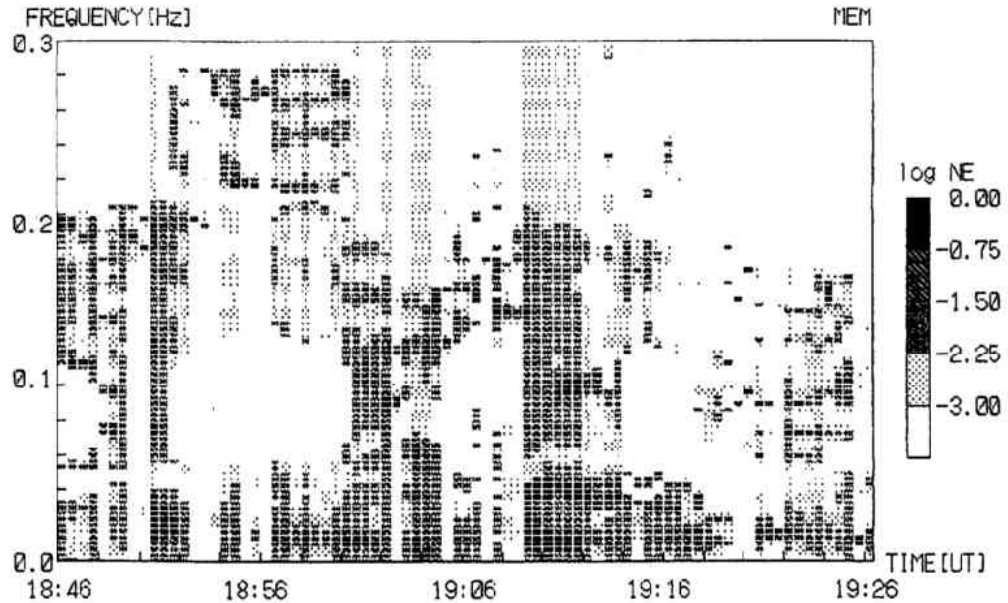

Fig. 6. The dynamic power spectrum estimation of irregular magnetic pulsations in the time interval of $18 \mathrm{~h} 46 \mathrm{~m}-19 \mathrm{~h} 26 \mathrm{~m}$ UT. The spectral peaks are distributed from the frequency of $0.1 \mathrm{~Hz}$ to $0.3 \mathrm{~Hz}$.

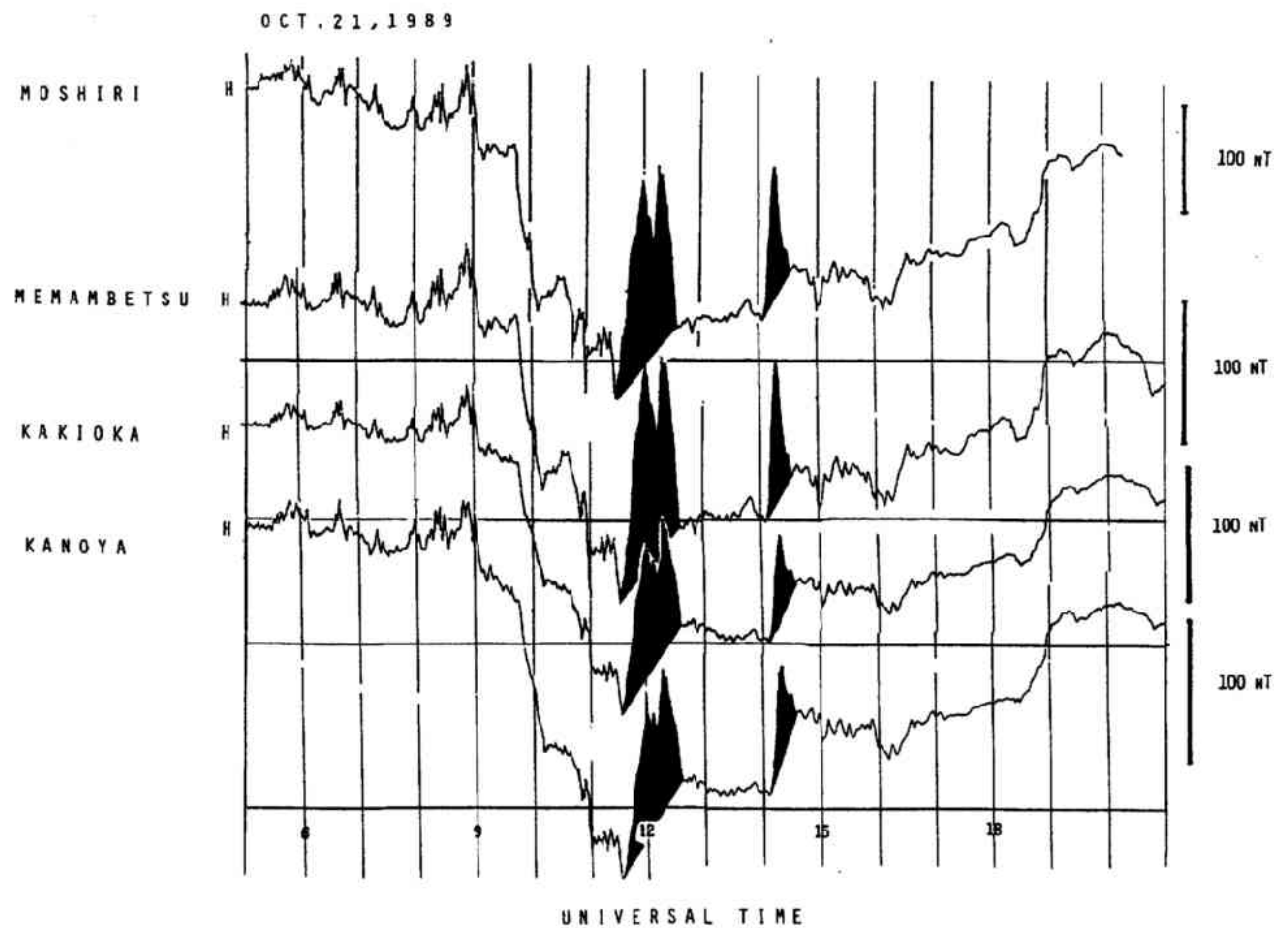

Fig. 7. The $H$-component magnetic perturbations in the magnetograms on October 21,1989 . Two distinct positive bays are shown in the shaded portions in the magnetograms. During the time intervals of two positive bays, the low latitude aurorae are observed in the north-eastern region of Hokkaido island. 


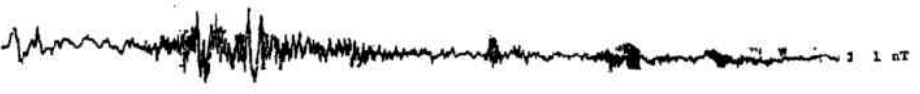

ONAGAKA

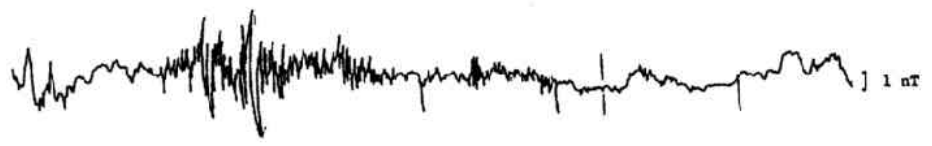

YONEZANA

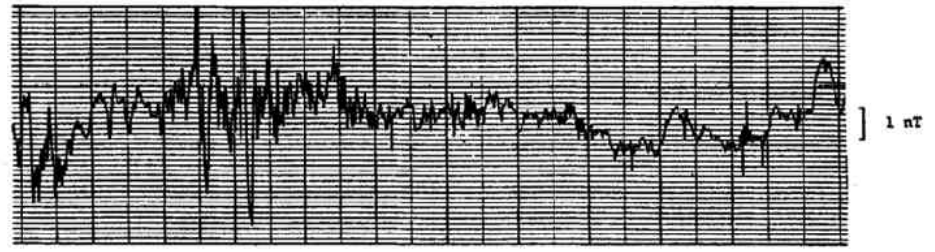

KA NOYA

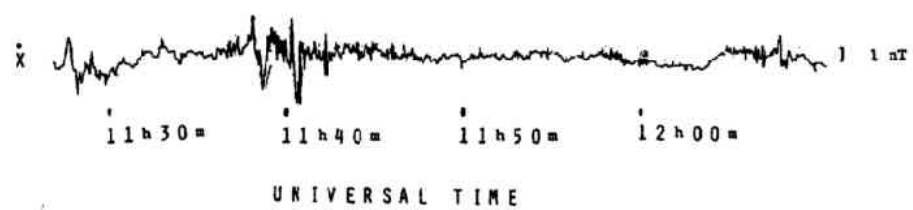

Fig. 8. The irregular magnetic pulsations accompanying the IPDP plasma wave event observed in association with low latitude aurora. Note that the onset time of irregular magnetic pulsations corresponds to the time of sudden brightening of $6300 \AA$ auroral luminosity.

and KNY observatories are shown in Fig. 8. It is clearly seen that the onset time of irregular magnetic pulsations corresponds to the time of sudden brightening of $6300 \AA$ auroral luminosity in the figure. Figure 9 shows filtered data observed at YNZ observatory. The data in the top panel are filtered in the frequency below $0.1 \mathrm{~Hz}$ and the data in the middle panel are filtered in the frequency band between $0.1 \mathrm{~Hz}$ and 0.2 $\mathrm{Hz}$. By comparing the $H$-component of the magnetogram (Fig. 7) with the IPDP plasma wave event (Fig. 9), it is particularly interesting to note that the time of the maximum amplitude of the first positive bay corresponds to the time of the maximum amplitude of the IPDP plasma wave event (12h00m UT).

The dynamic power spectrum estimation is also carried out for the time interval of $11 \mathrm{~h} 52 \mathrm{~m}-12 \mathrm{~h} 07 \mathrm{~m}$ UT, which is shown in Fig. 10. The result indicates that the frequency of wave packets with the maximum intensity is estimated to be $0.15 \mathrm{~Hz}$ in the time interval around $12 \mathrm{~h} 00 \mathrm{~m} \mathrm{UT}$.

The second example of irregular magnetic pulsations accompanying the IPDP plasma wave event during the time of low latitude aurora is shown in Fig. 11. The irregular magnetic pulsations begin at the time of $14 \mathrm{~h} 10 \mathrm{~m}$ UT which corresponds to the onset time of the second positive bay. The Pi 2 magnetic pulsations last for a quarter of an hour and then die out. A series of high frequency magnetic pulsations with small amplitude periodic oscillations is observed at the time of $14 \mathrm{~h} 25 \mathrm{~m}$ UT. The results of power spectrum analysis were already presented in the proceedings on the low latitude auroral events during October 21, 1989, Nagoya University (HIGUCHI et al., 1990; HIGUCHI, 1991). The development of IPDP plasma wave events in association with auroral substorms in high latitudes was investigated by FUKUNISHI (1969), HAYASHI et al. (1988), and KOLESZAR (1988). However, the study of IPDP plasma wave events observed in association with low latitude aurora was not discussed in their papers.

In order to estimate the convection electric field in the equatorial plane of the magnetosphere, the frequency increase as a function of time for the first example of the IPDP plasma wave event observed at YNZ observatory on October 21, 1989 is shown in Fig. 12. Although the width of IPDP spectrum is quite 


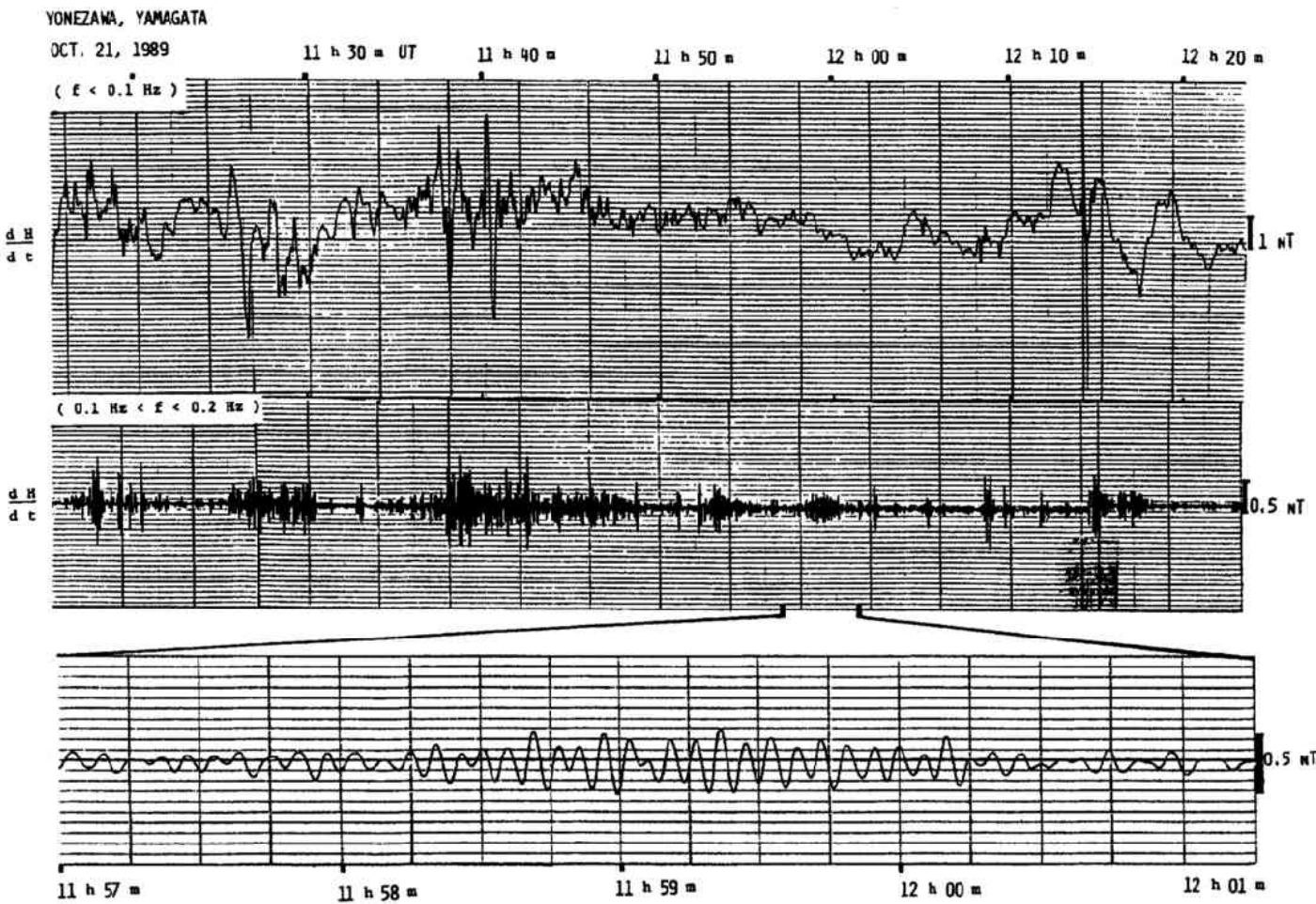

Fig. 9. Filtered data observed at YNZ observatory; The data in the top panel are filtered in the frequency below $0.1 \mathrm{~Hz}$, the data in the middle panel are filtered in the frequency band between $0.1 \mathrm{~Hz}$ and $0.2 \mathrm{~Hz}$ and the data in the bottom panel are the expansion of time scale for the high frequency wave packets.

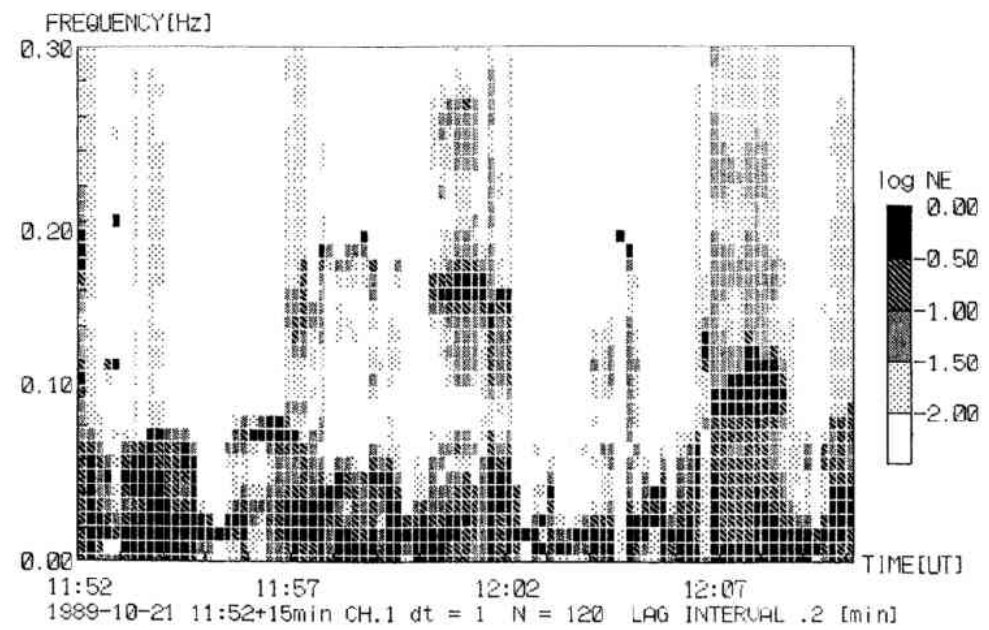

Fig. 10. The dynamic power spectrum estimation of irregular magnetic pulsations accompanying the IPDP plasma wave event in the time interval of $11 \mathrm{~h} 52 \mathrm{~m}-12 \mathrm{~h} 07 \mathrm{~m}$ UT. The spectral peak is estimated to be $0.15 \mathrm{~Hz}$ in the time interval around $12 \mathrm{~h} 00 \mathrm{~m}$ UT. 
MEMAMBETSU

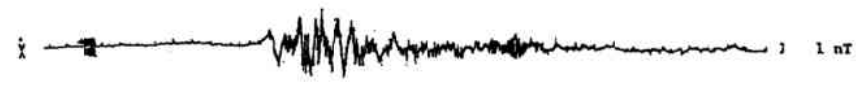

ONAGA XA
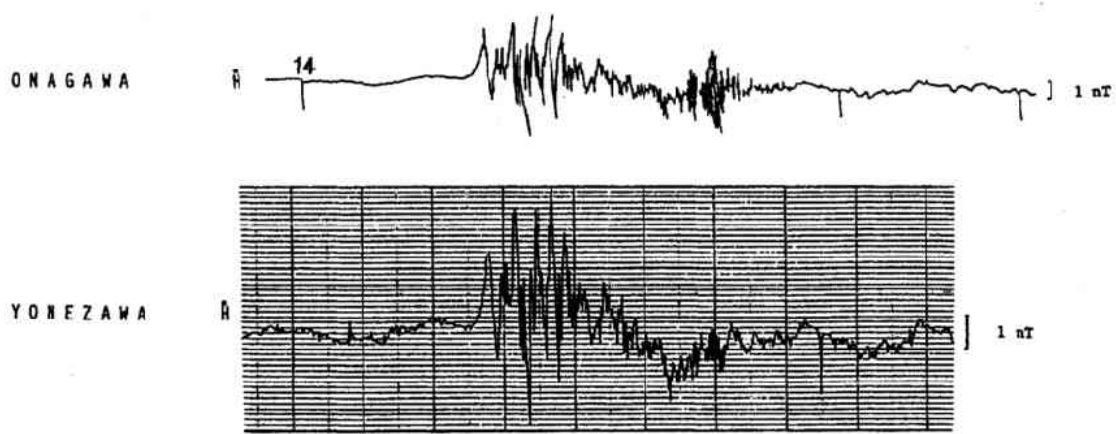

KANOYA

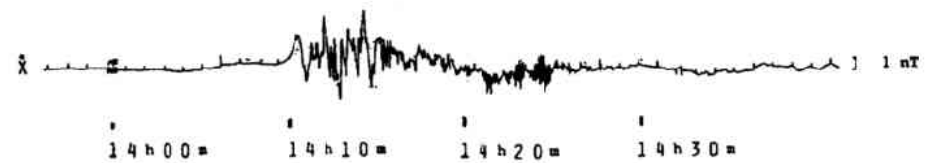

UKIVERSAL TIME

Fig. 11. Another example of irregular magnetic pulsations accompanying the IPDP plasma wave event observed in association with low latitude aurora. It is clearly seen that the high frequency wave packets are observed at the time of the maximum amplitude of positive bay.

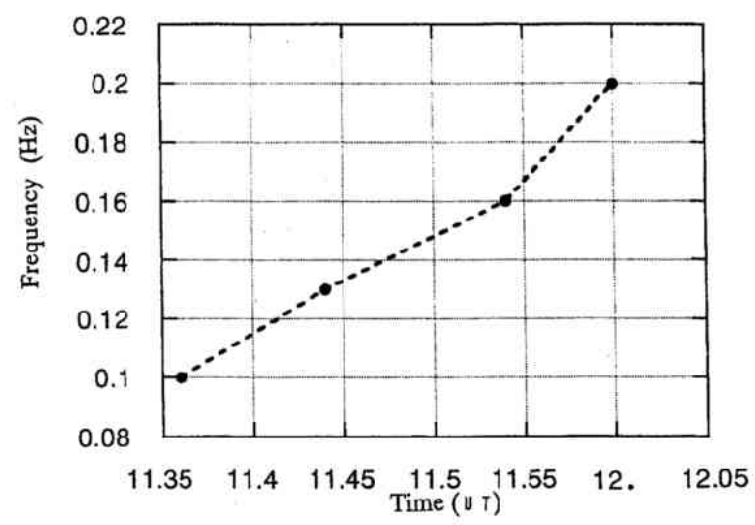

Fig. 12. The frequency increase as a function of time for the first example of IPDP plasma wave event in association with low latitude aurora observed at YNZ observatory on Oct. 21, 1989.

large, it is somewhat possible to measure an increase of midfrequency for the IPDP plasma wave event from the amplitude-time (waveform) appearance observed on chart records. The slope of mean midfrequency rise in the case of the first example in Fig. 9 is measured as $d f / d t=0.25 \mathrm{~Hz} / \mathrm{h}$. If we assume that the frequency increase of the IPDP plasma wave event is solely due to the radial convection of source region under the $E \times B$ drift, the relation between the frequency increase of IPDP plasma wave event and the westward convection electric field in the magnetosphere was given by TROITSKAYA et al. (1968). Thus, the inward convection velocity of source region is obtained as $V=1.02 \times 10^{-4} \mathrm{~L} \mathrm{~m} / \mathrm{sec}$ for $v=1.5$. One 
of the most ambiguous parameters in the simple model is the $L$ value of the IPDP source region. However, the DMSP-F9 satellite observation showed the existence of a localized region of precipitating low energy electrons just in the equatorward side of the ordinary auroral oval defined by an enhancement of precipitating electrons in several $\mathrm{KeV}$ (MIYAOKA et al., 1990). Thus, it is reasonable to assume that the source region of the IPDP plasma wave event in this case is located approximately less than $60^{\circ} \mathrm{N}$. In addition, the IPDP plasma wave event observed at YNZ observatory is a result of ionospheric duct propagation from a high latitude source region to low latitude observational region (FRASER and WAWRZYNIAK, 1978). Since there is a slight attenuation of ionospheric duct propagation, caused by the source region's unexpected proximity to YNZ observatory, it is presumed that the IPDP plasma wave event in association with low latitude aurora was observed at YNZ observatory. Tentatively, it is assumed that the source region is located around $L=4.0 \mathrm{Re}$ in this event. If the simple formula mentioned above for the IPDP plasma wave event is applied, the convection electric field in the magnetosphere is estimated to be $E=1.25 \mathrm{mV} / \mathrm{m}$. This value is twice larger than the electric field $(0.6 \mathrm{mV} / \mathrm{m})$ obtained by the EISCAT incoherent scatter rader during the IPDP plasma wave event in association with auroral substorm at high latitude (KANGAS et al., 1988). But, HEACOCK et al. (1976) have estimated the convection electric field to be $0.1-2.0 \mathrm{mV} / \mathrm{m}$ for the IPDP plasma wave event in the midnight sector. Therefore, it is necessary to further discuss the more sophisticated generation mechanism for the IPDP plasma wave event in association with low latitude aurora involving two or more superimposed possible generation mechanisms.

\section{Comparisons of Geosynchronous Satellite Data with YNZ Magnetic Observations}

In this section, magnetic field perturbations at geosynchronous orbit related to the period of low latitude auroral events will be investigated together with ground magnetic pulsation observations at YNZ observatory. The upper panel in Fig. 13 shows the magnetic field perturbations observed at GOES 7 and the bottom panel shows those observed at GOES 6 on Oct. 21, 1989. The periods indicated by the two vertical lines show the time intervals during which the low latitude aurorae were observed in the northern area of Hokkaido island. As for the time period of the first vertical line, the IPDP plasma wave event was registered at YNZ observatory which was already shown in Fig. 9. The sudden increase of $H$ and $V$ component magnetic fields at GOES $7(11 \mathrm{~h} 30 \mathrm{~m} \mathrm{UT})$ from negative to positive values after the gradual decrease of $H$ and $V$-component magnetic fields ( $11 \mathrm{~h} 00 \mathrm{~m} \mathrm{UT}$ ) indicates the transition of geomagnetic field configuration to the dipolarization from the more taillike magnetic field configuration (KOKUBUN and MCPHERRON, 1981; MCPHERRON, 1981; NAGAI, 1987). But, the onset time of sudden increase of $H$ component magnetic field at GOES 6 is at $11 \mathrm{~h} 50 \mathrm{~m}$ UT. Particularly, the $D$-component magnetic field at GOES 7 is positive after $12 \mathrm{~h} 00 \mathrm{~m}$ UT to $12 \mathrm{~h} 20 \mathrm{~m}$ UT, but the $D$-component magnetic field at GOES 6 remains a negative value. This means that the field-aligned current flowing down to the ionosphere is between the GOES 6 and GOES 7 geosynchronous satellite orbit (SAKURAI and MCPHERRON, 1983).

It is clearly seen that the total magnetic field intensity at GOES 7 also increases from $150 \mathrm{nT}$ at $11 \mathrm{~h} 00 \mathrm{~m} \mathrm{UT}$ to $250 \mathrm{nT}$ at $1 \mathrm{lh} 25 \mathrm{~m} \mathrm{UT}$. This abnormal increase of total magnetic field intensity means large accumulation of magnetic field energy which is suddenly dissipated by the reconnection process during the expansive phase of substorms. It is of interest to note that the GOES 6 observation lagged behind the observation at GOES 7 for 10 minutes in spite of its longitudinal position near the midnight sector. Namely, GOES 7 observed the initial increase of total magnetic field intensity at $11 \mathrm{~h} 00 \mathrm{~m}$ UT, but GOES 6 observed the initial increase of total magnetic field intensity at $11 \mathrm{hl} 0 \mathrm{~m}$ UT. This means that the initial reconnection region of substorm in this event is located inside the geosynchronous satellite orbit, and then the transition from the taillike configuration to the dipolelike configuration is propagated outside the position of geosynchronous orbit. At the same time, the high energy ring current particles $(30 \mathrm{KeV})$ are injected inside the geosynchronous orbit. Therefore, the IPDP plasma wave event observed at YNZ observatory in association with low latitude aurora can be generated by the wave-particle interaction at the plasmapause.

As for the time period of the second vertical line, it is also shown that the IPDP plasma wave event 
OCT, 21, 1989

GOES 7

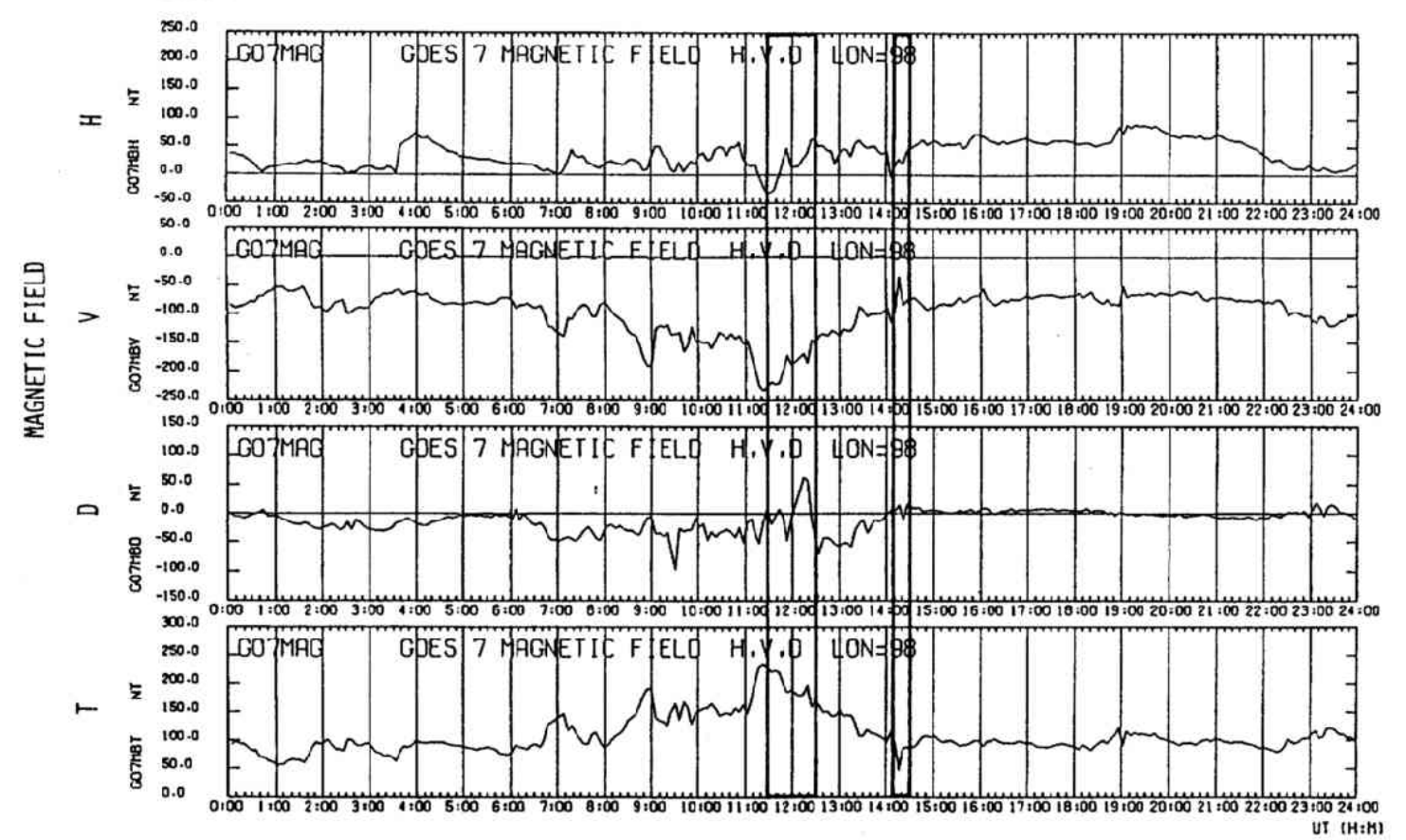

GOES 6

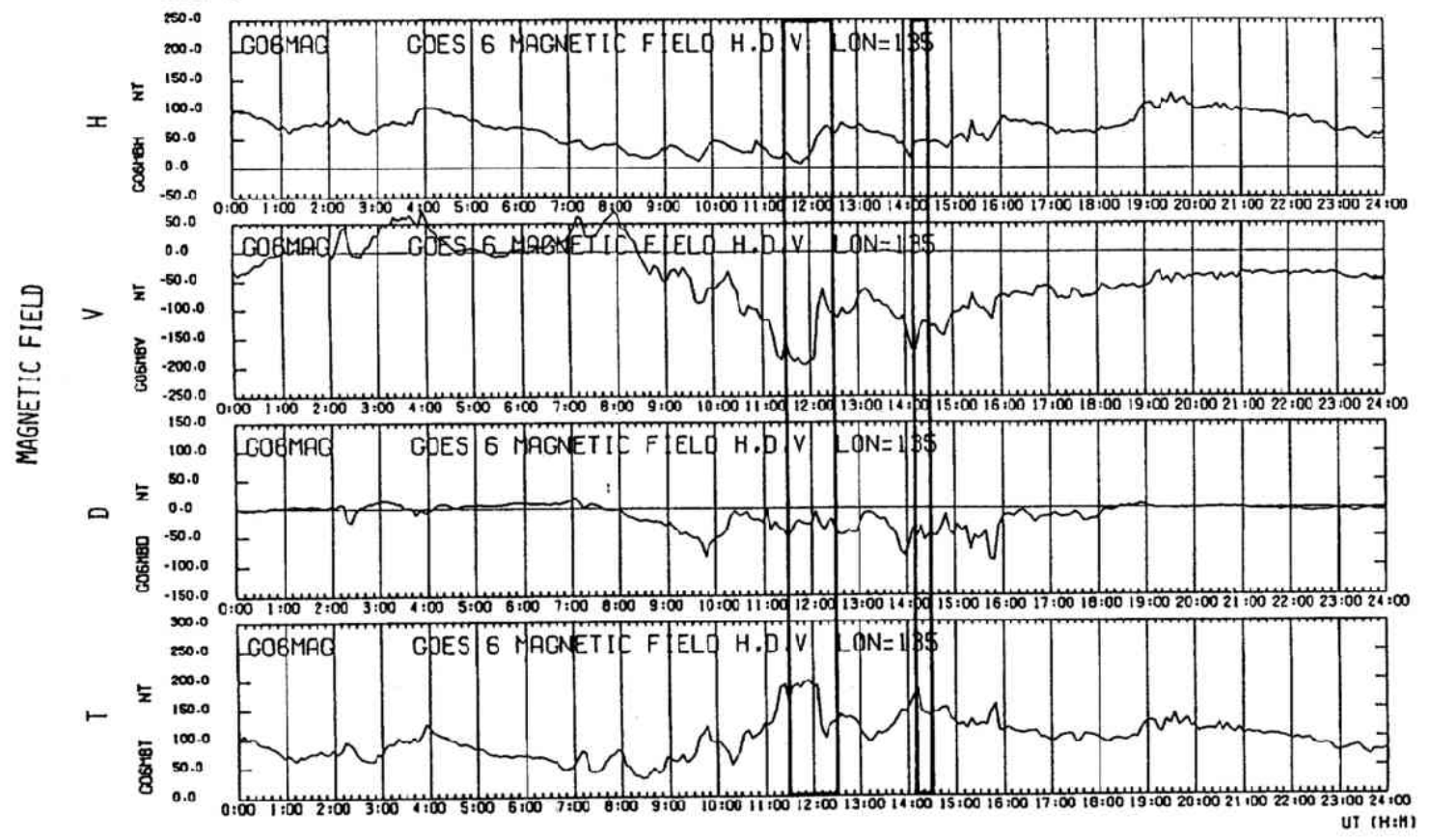

Fig. 13. The magnetic field perturbations at geosynchronous orbit on October 21,1989 . The time period indicated by the two vertical lines shows the time intervals during which the low latitude aurorae were observed in the northern area of Hokkaido island. 

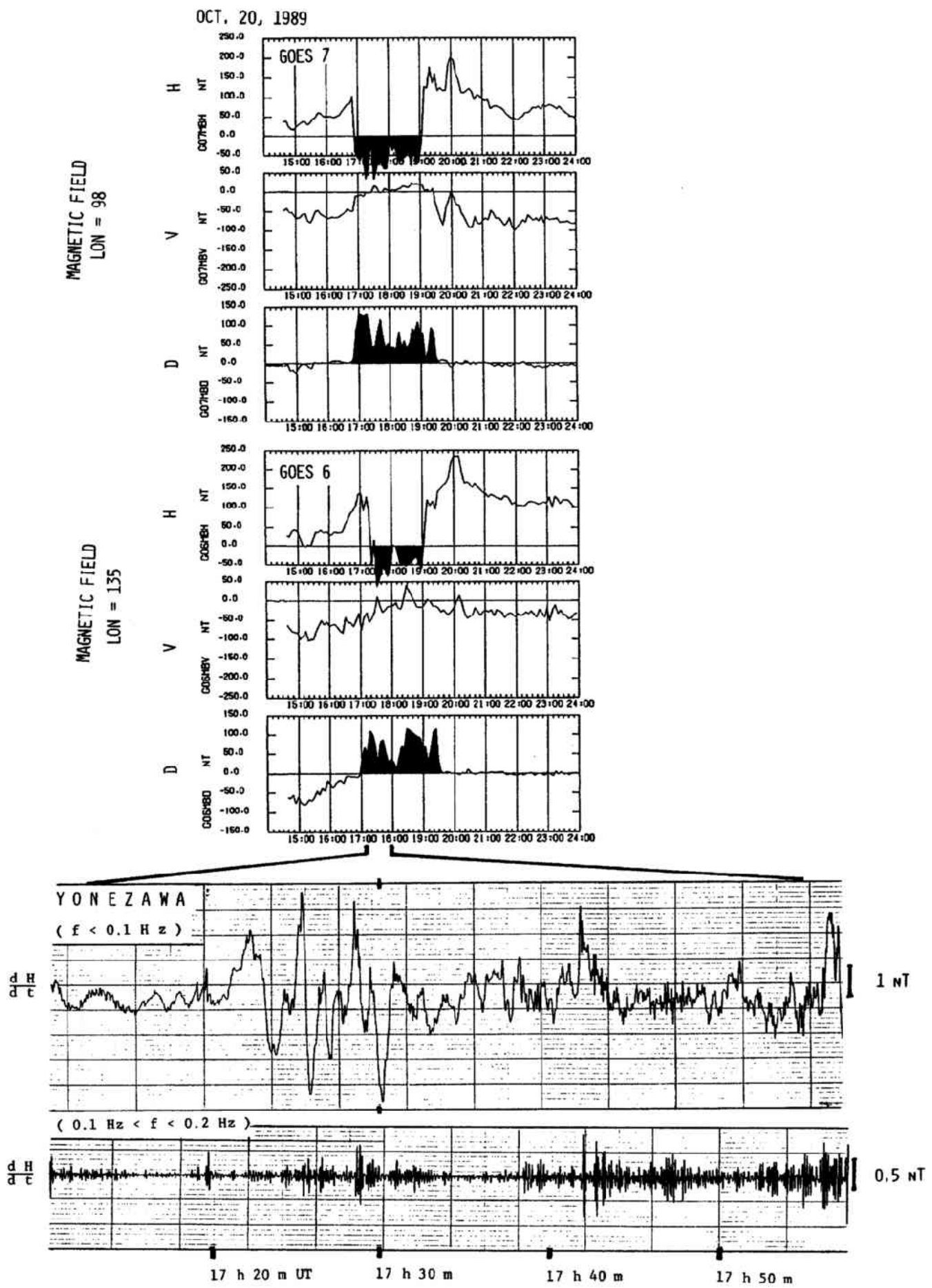

Fig. 14. In the upper panel, the magnetic field perturbations at geosynchronous orbit: GOES 6 and 7, while the magnetopause is suddenly compressed inside the geosynchronous orbit. In the bottom panel, the $H$-component magnetic field perturbations observed at YNZ observatory. Note that the transient magnetic field oscillations with the period of approximately 100 seconds are observed while the sudden compression of the magnetopause at GOES 6 occurs. 
was registered at YNZ observatory which was already presented in Fig. 11. Similar to the previous event, the sudden increase of $H$-component magnetic field after the gradual decrease of $H$-component magnetic field at $14 \mathrm{~h} 00 \mathrm{~m} \mathrm{UT}$, and the sudden increase of $V$-component magnetic field at GOES 7 indicate the transition of geomagnetic field configuration to dipolarization from the more taillike magnetic field configuration. Curiously, there is no time difference between GOES 6 and 7 satellites in this event. The $D$-component magnetic field at GOES 7 is approximately zero, but the $D$-component magnetic field at GOES 6 is negative $(-50 \mathrm{nT})$. It is noteworthy that the IPDP plasma wave events observed in conjunction with low latitude aurora occur while the magnetic field perturbations at GOES 6 and 7 begin to recover the dipolelike configuration from the more taillike magnetic field configuration. In the past, RoXBURGH (1970) maintained that the IPDP plasma wave events on the ground occur in simultaneity with the increase in the magnetic field strength at the overhead geosynchronous orbit. Although GOES 6 and 7 satellites are not located on the longitudinal meridian of YNZ observatory, it seems that the IPDP plasma wave events observed at YNZ observatory in association with low latitude aurora have the same tendency as Roxburgh's conclusion (WATANABE, 1991).

On the other hand, the results of magnetic field observations at GOES 6 and 7 on Oct. 20, 1989 are shown in the upper panel of Fig. 14. The sudden dropout of $H$-component magnetic field and the sudden positive deflection in the $D$-component magnetic field are emphasized by the shaded portions. It is speculated that the GOES 6 and 7 satellites are located outside the magnetosphere, i.e., in the magnetosheath, because of the sudden compression of the magnetosphere due to pressure increase of the solar wind. In other word, it is considered that the inward motion of the magnetopause is due to the reconnection of the magnetic field or erosion of the geomagnetic field in the presence of a southward interplanetary magnetic field (CAHILL and WINCKLER, 1992). The compression of the magnetopause lasted for approximately two hours and abruptly recovered at $19 \mathrm{~h} 00 \mathrm{~m}$ UT. The transient magnetic field oscillations with the period of approximately 100 seconds were registered at YNZ observatory which is shown in the bottom panel of Fig. 14. The onset time of sudden compression on the basis of the ground transient magnetic field oscillations at YNZ observatory is $17 \mathrm{~h} 20 \mathrm{~m}$ UT, which corresponds to the time of sudden dropout of $\mathrm{H}$ component magnetic field at GOES 6 , but the sudden positive deflection in the $D$-component magnetic field already started just before $17 \mathrm{~h} 00 \mathrm{~m}$ UT. The sudden dropout in the $H$-component magnetic field and the sudden positive deflection in the $D$-component magnetic field at GOES 7 simultaneously occurred at $16 \mathrm{~h} 50 \mathrm{~m}$ UT. Note that the onset time of the sudden dropout in $H$-component magnetic field at GOES 6 was 20 minutes behind that at GOES 7, because of the different longitude at the satellite position. On the other hand, the sudden recovery time of $H$-component magnetic field perturbations began at the time of $19 \mathrm{~h} 00 \mathrm{~m} \mathrm{UT}$, but the value of $D$-component magnetic field perturbations still remains positive at the time of $19 \mathrm{~h} 00 \mathrm{~m}$ UT until $19 \mathrm{~h} 50 \mathrm{~m}$ UT. The irregular magnetic pulsations (Pi C) observed at YNZ observatory are already shown in Fig. 5, when the magnetic field at the satellite position suddenly recovered.

\section{Discussion and Conclusions}

TROITSKAYA (1961) reported that the irregular magnetic pulsations with periods of 6 seconds (SIP) have close correlations with aurora. Her results indicated that the predominant period of SIP coincided with the main period of intensity change of aurora. MCPHERRON et al. (1968) made an investigation about the correlation between geomagnetic micropulsations and electron precipitation occurring during auroral substorms. In the midnight region, broadband noise bursts and impulsive electron precipitations were related to the auroral breakup. Band limited irregular magnetic pulsations $(\mathrm{Pi} \mathrm{C}$ ) and modulated electron precipitations of 5 to 10 seconds in period occurred in early morning hours in conjunction with negative bays. The IPDP plasma wave events with no relationships to electron precipitations were also related to auroral substorms. KANGAS et al. (1979) recognized that Pi B magnetic pulsations are observed during distortions of the auroral arc which enclose a local region of upward directed field-aligned currents (REID, 1976; WILHELM et al., 1977). The source region of Pi B magnetic pulsations was located at a relatively low altitude, i.e., the altitude of the double layer that was estimated to be $6000 \mathrm{~km}$. BösINGER et al. (1981) 
also revealed that Pi B magnetic pulsations are generated at the time of auroral intensification when the localized upward field aligned current develops. The generation of Pi B magnetic pulsations was due to fluctuations of a localized upward field aligned current. The fluctuations may be caused by the inherent variations of a double layer occurring as a consequence of the field aligned current.

Concerning the Pi B magnetic pulsations observed in association with auroral substorms in high latitudes, all above mentioned authors have pointed that a possible source of $\mathrm{Pi} \mathrm{B}$ could be related to upward field-aligned currents associated with the auroral breakup. A possible source of $\mathrm{PiC}$, however, could be a result of fluctuations in ionospheric currents related to auroral electrojets. The IPDP plasma wave events observed in association with auroral substorms could be a manifestation of wave-particle interactions in the region of plasmapause in the magnetosphere.

Although there are few investigations of magnetic perturbations in association with low latitude aurora, TINSLEY et al. (1986) reported that the low latitude aurorae have spectral characteristics which are quite distinct from the ordinary aurora excited by keV electrons. The brightest emissions occur when the $H$-component of magnetic field is minimum and specifically when positive $H$ excursions take place. The intensity variations of low latitude aurorae show large amplitude changes on a time scale of 0.1 hour, which are closely related to the magnetic signatures of the storm time ring current system. The short time scale of these fluctuations implies that the ring current is incompletely shielded, allowing ionospheric currents and the injection of ring current to descend to unusually low latitudes. On the other hand, FUKUSHIMA (1991) proposed an interesting scenario for the occurrence mechanism of positive bays, attributing them to a local reduction in the height-integrated Pedersen conductivity of the ionosphere in the region of low latitude aurora. It was assumed that the geomagnetic bays in the night of Oct. 21, 1989, over the western pacific region brought a great enhancement of ionospheric conductivity in the evening sector in the auroral zone down to a geomagnetic latitude of $50^{\circ} \mathrm{N}$ or even lower, with a bulge for the unusual low latitude aurora. As a consequence of the conductivity increase of the auroral zone ionosphere in the evening sector, intense Cowling currents flow westward in the region of enhanced conductivity. At the same time, positive (negative) electric charges are accumulated on the western (eastern) end of the region of enhanced conductivity. This transient electric field affects the height integrated conductivity. The eastward transient electric field drifts up electrons and ions so as to decrease the Pedersen conductivity of the ionosphere. It was speculated that the hole of Pedersen conductivity appeared just outside the region of enhanced conductivity. This effect is equivalent to the current system, which consists of the southward concentrated current in the area of Pedersen conductivity hole with its return currents in the surrounding region. OGUTI (1991) also insisted that a possible source of low latitude aurora was not specifically of low latitude, but most likely was the southward expansion branch of an aurora in the normal auroral zone. Therefore, it will be necessary to carry out a quantitative discussion on each physical process involved in the generation mechanisms of low latitude aurora.

In summary, $\mathrm{Pi} 1$ magnetic pulsations and IPDP plasma wave events related to the low latitude aurora were observed at YNZ observatory on October 20 and 21, 1989. The Pi B superposed on Pi 2 magnetic pulsations occurred at the onset time of positive bays in the magnetograms. The Pi B magnetic pulsations were observed in the midnight quadrant, but $\mathrm{PiC}$ magnetic pulsations occurred in the early morning hours. The power spectrum estimation indicated that the spectral peaks of $\mathrm{PiC}$ magnetic pulsations were mainly distributed in the frequency band between $0.1 \mathrm{~Hz}$ and $0.2 \mathrm{~Hz}$ at YNZ observatory. In addition, IPDP plasma wave events were observed during the low latitude aurora that occurred in the late evening to midnight quadrant. Furthermore, it is noteworthy that the IPDP plasma wave events observed in association with low latitude aurora occurred while the magnetic field perturbations at geosynchronous orbit began to recover the dipolelike configuration from the more taillike magnetic field configuration. Even in the case of low latitude aurora, it seems that the genetical characteristics of $\mathrm{Pi} 1$ magnetic pulsations and IPDP plasma wave events were explained in terms of a model of micropulsation substorm as proposed by AKASOFU (1968) regarding the polar aurora in high latitudes, except a short time duration of magnetic fluctuation and a particular transient low latitude expansion of auroral zone. Besides, the magnetic field perturbations at the geosynchronous orbit were compared with the ground magnetic 
pulsations observed at YNZ observatory. The transient magnetic field oscillations were observed at the time of sudden compression of the magnetopause inside the geosynchronous orbit.

The author wishes to thank K. Higuchi, T. Watanabe, T. Kitamura, K. Yokoto, H. Fukunishi, H. Oya, S. Shibuya, N. Sato, K. Kobayashi and T. Tamura for their encouragement and suggestions during many years. Ground magnetic data were provided by Kakioka magnetic observatory (M. Kuwashima, S. Fujita and S. Kadokura), Onagawa and Moshiri magnetic observatories (T. Takahashi, Y. Tanaka and K. Yumoto). Satellite magnetic data were supplied from the Solar-Terrestrial Environmental Research Laboratory, Nagoya University. Thanks are due to technical staffs and graduate students (T. Yoshida, A. Horikawa and S. Yanagi) for their help during the experiment of this study. The author also appreciates many constructive comments made by the referee.

\section{REFERENCES}

AKAsofu, S-I., Micropulsation substorm, in Polar and Magnetospheric Substorms, pp. 155-173, D.Reidel Publ. Comp., Dordrecht, 1968.

Bosinger, T., K. Alanko, J. Kangas, H. Opgenoorth, and W. Baumjohann, Correlations between Pi B type magnetic micropulsations, auroras and equivalent current structures during two isolated substorms, J. Atmos. Terr. Phys., 43, 933-945, 1981.

CAHILL, L. J., Jr. and J. R. WINCKLER, Periodic magnetopause oscillations observed with the GOES satellite on March 24, 1991, J. Geophys. Res., 97, 8239-8243, 1992.

CAMPBell, W. H. and S. MAtsushitA, Auroral zone geomagnetic micropulsations with periods of 5 to 30 seconds, J. Geophys. Res., 67, 555-573, 1962.

CoRnwall, J. M., Turbulent loss of ring current protons, J. Geophys. Res., 75, 4699-4708, 1970.

CORnWALL, J. M., F. V. CoRoniti, and R. M. THORNE, A unified theory of SAR arc formation at the plasmapause, J. Geophys. Res., 76, 4428-4445, 1971.

Coroniti, F. V. and C. F. KenNel, Auroral micropulsation instability, J. Geophys. Res., 75, 1863-1878, 1970.

Engebretson, M. J., L. J. CAHILL, Jr., R. L. ARnoldy, S. B. Mende, and T. J. Rosenberg, Correlated irregular magnetic pulsations and optical emissions observed at Siple station, antarctica, J. Geophys. Res., 88, 4841-4852, 1983.

Fraser, B. J. and S. WAwrZyniaK, Source movements associated with IPDP pulsations, J. Atmos. Terr. Phys., 40, 1281-1288, 1978.

FUKUNISHI, H., Occurrence of sweepers in the evening sector following the onset of magnetospheric substorms, Rep. Ionos. Space Res., Jpn, 23, 21-34, 1969.

FukuShima, N., Geomagnetic bays with different $D / H$ ratios observed in association with low latitude aurora on October 21,1989 , Proc. on Low Latitude Auroral Events during October 20 and 21, 1989, 2, 187-193, 1991.

GENDRIN, R., Substorm aspects of magnetic pulsations, Space Sci. Rev., 11, 54-130, 1970.

Hayashi, K., T. Yamamoto, S. Kokubun, T. Oguti, T. Ogawa, N. Iwagami, T. Araki, T. I. Kitamura, O. Saka, K. Makita, N. Sato, T. Watanabe, R. E. Horita, D. J. McEwen, J. S. Kim, and A. V. Egeland, Multi-station observation of IPDP micropulsations-Two dimensional distribution and evolution of the source regions, J. Geomag. Geoelectr., 40, 583-619, 1988.

HeAcock, R. R., Two subtypes of type Pi micropulsations, J. Geophys. Res., 72, 3905-3917, 1967.

Heacock, R. R. and R. D. Hunsucker, Type Pi 1-2 magnetic field pulsations, Space Sci. Rev., 28, 191-221, 1981.

HEACOCK, R. R., D. J. HENDERSON, J. S. REID, and M. KIVININ, Type IPDP pulsation events in the late evening-midnight sector, J. Geophys. Res., 81, 273-280, 1976.

HIGUCHI, Y., ULF pulsations observed in association with low latitude aurora, Proc. on Low Latitude Auroral Events during October 20 and 21, 1989, 2, 213-217, 1991.

HIGUCHI, Y., A. HoRIKAWA, and S. YANAGI, Possible causes of Pc 2 oscillations occurring during a main phase of geomagnetic storm, EOS, 71, 1814, 1990.

JACoBs, J. A., Geomagnetic micropulsations, in Physics and Chemistry in Space, 1, 45-63, Springer, New York, 1970.

KAN, J. R. and R. R. HEACOCK, Generation of irregular (Type Pi C) pulsations in the plasma sheet during substorms, J. Geophys. Res., 81, 2371-2376, 1976.

Kangas, J., T. Pikkarainen, Yu. Golikov, L. Baransky, V. A. Troitskaya, and V. Sterlikava, Burst of irregular magnetic pulsations during the substorm, J. Geophys., 46, 237-247, 1979.

KANGAS, J., A. AIKIO, and T. PIKKARAINEN, Radar electric field measurement during an IPDP plasma wave event, Planet. Space Sci., 36, 1103-1109, 1988.

Koleszar, T. W., The generation of IPDP micropulsations, with special attention to frequency shift mechanisms, Ph.D. Thesis, 233 pp., Univ. of British Columbia, 1988.

KoKubun, S. and R. L. MCPherron, Substorm signatures at synchronous altitude, J. Geophys. Res., 86, 11265-11277, 1981. 
LYSAK, R. L., Theory of auroral zone Pi B puisation spectra, J. Geophys. Res., 93, 5942-5946, 1988.

McPherron, R. L., Substorm associated micropulsations at synchronous orbit, J. Geomag. Geoelectr., 32, 57-73, 1981.

McPherron, R. L., G. K. PARKs, F. V. Coroniti, and S. H. WARD, Studies of the magnetospheric substorm, J. Geophys. Res., 73, $1697-1713,1968$.

MiYaoka, H., T. Hirasawa, K. Yumoto, and Y. TANaKa, Low latitude aurorae on October 21, 1989, Proc. Japan Acad., 66, 47$51,1990$.

NAGAI, T., Field-aligned currents associated with substorms in the vicinity of synchronous orbit, 2. GOES 2 and GOES 3 observations, 92, 2432-2446, 1987.

OGUTI, T., Source of middle (low) latitude aurora, Abstract of the 90th Meeting Soc. of Geomagn. Earth, Planet. and Space Sci. Jpn., A32-01, 1991.

REID, J. S., An ionospheric origin for Pi 1 micropulsations, Planet. Space Sci., 24, 705-710, 1976.

Rostoker, G., Geomagnetic micropulsations, Fundamentals of Cosmic Physics, 4, 211-311, 1979.

RoXBURGH, K. R., A theory for the generation of "intervals of pulsation of diminishing period", Ph.D Thesis, 92 pp., Univ. of British Columbia, 1970.

SAITo, T., Geomagnetic pulsations, Space Sci. Rev., 10, 319-412, 1969.

SAkURAI, T. and R. L. MCPherron, Satellite observations of Pi 2 activity at synchronous orbit, J. Geophys. Res., 88, 7015-7027, 1983.

SAmson, J. C., Geomagnetic pulsations and plasma waves in the earth's magnetosphere, Geomagnetism, 4, 481-592, 1991.

Tinsley, B. A., R. Rohrbaugh, H. Rassoul, Y. Sahai, N. R. Teixeira, and D. Slater, Low-latitude aurorae and storm time current systems, J. Geophys. Res., 91, 11257-11269, 1986.

Troitskaya, V. A., Pulsation of the earth's electromagnetic field with periods of 1 to 15 seconds and their connection with phenomena in the high atmosphere, J. Geophys. Res., 66, 5-18, 1961.

Troitskaya, V. A., R. V. SChepetNov, and A. V. GulelMi, Estimate of electric fields in the magnetosphere from the frequency drift of micropulsations, Geomagn. Aerono., 8, 634, 1968.

Watanabe, T., Annual report on space and planetary physics, Univ. of British Columbia, 11-12, 1991.

WiLheLM, K., J. W. MUNCH, and G. KREMSER, Fluctuations of the auroral zone current system and geomagnetic pulsations, $J$. Geophys. Res., 82, 2705-2716, 1977.

Yumoto, K., K. Takahashi, T. Saito, F. W. Menk, B. J. Fraser, T. A. Potemra, and L. J. Zanetti, Some aspects of the relation between Pi 1-2 magnetic pulsations observed at $L=1.3-2.1$ of the ground and substorm associated magnetic field variations in the near-earth magnetotail observed by AMPTE CCE, J. Geophys. Res., 94, 3611-3618, 1989. 